\title{
Portable device for generation of ultra-pure water vapor feeds
}

\author{
P. Velin, ${ }^{1, a)}$ U. Stenman, ${ }^{2}$ M. Skoglundh, ${ }^{1}$ and P.-A. Carlsson ${ }^{1}$ \\ ${ }^{1}$ Department of Chemistry and Chemical Engineering, Competence Centre for Catalysis, Chalmers University \\ of Technology, SE-412 96 Göteborg, Sweden \\ ${ }^{2}$ Department of Space, Earth and Environment, Chalmers University of Technology, SE-412 96 Göteborg, Sweden
}

(Received 5 July 2017; accepted 18 October 2017; published online 3 November 2017)

\begin{abstract}
A portable device for the generation of co-feeds of water vapor has been designed, constructed, and evaluated for flexible use as an add-on component to laboratory chemical reactors. The vapor is formed by catalytic oxidation of hydrogen, which benefits the formation of well-controlled minute concentrations of ultra-pure water. Analysis of the effluent stream by on-line mass spectrometry and Fourier transform infrared spectroscopy confirms that water vapor can be, with high precision, generated both rapidly and steadily over extended periods in the range of $100 \mathrm{ppm}$ to 3 vol. \% (limited by safety considerations) using a total flow of 100 to $1500 \mathrm{ml} / \mathrm{min}$ at normal temperature and pressure. Further, the device has been used complementary to a commercial water evaporator and mixing system to span water concentrations up to 12 vol. \%. Finally, an operando diffuse reflective infrared Fourier transform spectroscopic measurement of palladium catalysed methane oxidation in the absence and presence of up to 1.0 vol. \% water has been carried out to demonstrate the applicability of the device for co-feeding well-controlled low concentrations of water vapor to a common type of spectroscopic experiment. The possibilities of creating isotopically labeled water vapor as well as using tracer gases for dynamic experiments are discussed. Published by AIP Publishing. https://doi.org/10.1063/1.4994245
\end{abstract}

\section{INTRODUCTION}

Influence of water vapor is important to consider in the study of heterogeneous catalysts, ${ }^{1-5}$ surfaces, ${ }^{6-9}$ adhesives, ${ }^{10-13}$ and semiconductor devices. ${ }^{14-16}$ Such research requires the generation of accurate and precise water vapor environments that can simulate realistic conditions experimentally. The present work presents a robust portable device for the generation of ultra-pure water vapor to be used as an addon component to laboratory chemical flow reactors or other sample environments depending on the goal at hand.

Screening the open literature one finds several water vapor delivery systems based on saturation of a carrier gas, e.g., helium, nitrogen, or air, with water from a liquid reservoir. Commonly reported systems include the following: humidifiers, where the carrier gas is passed over the surface of liquid water at a defined temperature; ${ }^{1-4,17,18}$ water bubblers, where the carrier gas passes through liquid water contained in a flask; $8,9,16,19$ syringe pumps, for controlled water supply into a hot gas stream; ${ }^{20}$ and systems for controlled evaporation and mixing (CEM) where liquid mass flow controllers (1-MFCs) are used to control a pressurised water flow into an apparatus for heating and evaporation of the water into the carrier gas. ${ }^{21}$ From the design of these systems, one may claim limitations in terms of accuracy and stability when targeting low water vapor concentrations, especially for low gas flows, where precision plays a decisive role. Further, impurities in the water reservoir may be an issue. Sufficiently deionized water may not be available and complete avoidance of dissolution of atmospheric compounds such as carbon dioxide is difficult. Practically, the non-negligible investments in CEM systems often lead to the

a)Electronic mail: peter.velin@chalmers.se fact that such systems are utilized for different liquids and thus residues from other uses may remain in the reservoir tank due to insufficient cleaning.

Two patents were approved in the early 2000s describing similar water vapor generators (WVG), targeting the semiconductor industry. ${ }^{22,23}$ The patents contain information about how the devices enable production of ultra-high pure water vapor via catalytic oxidation of hydrogen over platinum-coated catalysts. The latter patent removes the carrier gas by absorbing water vapor in a sorption vessel placed after the catalyst. Turning of the gas flow and subsequently heating the sorption material release a $100 \%$ pure water vapor flow safely with high reproducibility. Reminiscent of realistic process conditions, this type of combustion vapor would be suitable in a research field such as catalysis as an alternative solution to previously mentioned pyrogenic delivery systems, especially in the cases where well-controlled low concentrations of water are needed.

Herein, we report on the design, construction, and evaluation of a portable device for the generation of water vapor from catalytic hydrogen oxidation. Accurate water concentrations ranging from $100 \mathrm{ppm}$ to $10 \mathrm{vol}$. \% using total flows from 100 to, at least, $1500 \mathrm{ml} / \mathrm{min}$ can be obtained by controlled feeding of $\mathrm{H}_{2}, \mathrm{O}_{2}$, and $\mathrm{Ar}$ over a catalytic bed $\left(\mathrm{Pt} / \mathrm{SiO}_{2}\right)$. The precision of the water vapor flow rate is dependent on the precision of the gas mass flow controllers (g-MFCs) and purity of the gas feeds. The device can be operated stoichiometrically and in critical cases, oxygen or hydrogen-free water vapor conditions are ensured by operating in hydrogen or oxygen excess, respectively. We also show that the device can be operated together with a commercial CEM system so as to span a wider range of water concentrations. Finally, we demonstrate how the device can be used for a sensitive operando infrared 
spectroscopic measurement of the inhibiting effect of water vapor on the catalytic oxidation of methane over a traditional alumina supported Pd-based catalyst.

\section{EXPERIMENTAL SECTION}

\section{A. Design criteria and integration of the portable water vapor device}

The portable water generator (PWG) device, of which drawings are presented in Fig. 1 and sub-parts listed in Table I, has been built to meet a number of design criteria. First, it should be small, light, and robust for easy transportation and handling, which also facilitates a long lifetime in practice. Additionally, it should be easily connected to other gas systems and easy to operate. The temperature should be adjustable so that it can be used in many environments that may have different requirements on hot equipment as well as for enabling occasional regeneration of the catalyst if necessary. Also, the device should respond quickly so as to facilitate rapid start-up/shut-down and step- and pulse-response experiments.

The interior of the PWG device is comprised of three sections, manufactured by lathing and drilling a bar of stainless steel, of varying lengths, and internal and external diameters, that serve specific roles: the inlet section (or left side), where the feed enters; the central section, where the catalysts (described in detail below) reside during operation; the outlet section (or right side), where the feed exits. The central section is $50 \mathrm{~mm}$ long with an internal diameter of $8 \mathrm{~mm}$ and an external diameter of $30 \mathrm{~mm}$. The inlet section also has an $8 \mathrm{~mm}$ internal diameter but with an external diameter of $14 \mathrm{~mm}$ and a length of $35 \mathrm{~mm}$. The outlet section has the same length and external diameter as the inlet section; however, the internal diameter is decreased to $5 \mathrm{~mm}$ to allow positioning of catalysts in the central section.

Male connectors (SS-600-1-4, Swagelok) are welded to the inlet and outlet sections for fast and durable connection to various gas feed systems by the use of suitable standard reducers. A nozzle heating element with a diameter of $30 \mathrm{~mm}$ and a length of $40 \mathrm{~mm}$ is sealed around the central section to provide stable and uniform heating. The nozzle heater includes a thermocouple and an internal thermostat, which together with a simple proportional integral differential (PID) regulator (Eurotherm 3508) controls the temperature. The maximum
TABLE I. List and description of parts in the PWG device.

\begin{tabular}{lcccc}
\hline \hline Item & Description & Material & Part number & Qty \\
\hline 1 & Reactor cover & $316 \mathrm{~L}$ & & 1 \\
2 & Reactor cover & $316 \mathrm{~L}$ & & 2 \\
3 & Nozzle heater, SES & & \\
& $\varnothing=30 \mathrm{~mm}$ & & & \\
& $1=40 \mathrm{~mm}$ & & & 1 \\
& $230 \mathrm{~W}, 230 \mathrm{~V}$ & & & \\
4 & Male pipe weld & $316 \mathrm{~L}-600-1-4$ & 1 \\
& Connector, Swagelok & & & 2 \\
5 & Insulation & Mineral wool & & 1 \\
6 & Catalyst & Pt/SiO & \\
7 & Male pipe weld & $316 \mathrm{~L}$ & SS-600-1-4 & \\
& Connector, Swagelok & & & 1 \\
8 & Lathed steel bar & $316 \mathrm{~L}$ & & 2 \\
9 & Metal standing & $316 \mathrm{~L}$ & & \\
\hline \hline
\end{tabular}

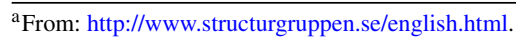

power is $230 \mathrm{~W}$, with a voltage of $230 \mathrm{~V}$ AC. A layer of quartz wool insulates the interior part of the PWG device and protective metal shields keep the insulation in place and make the reactor robust. Furthermore, two metal stands with drilled holes are welded to the metal side shields for easy mounting either horizontally or vertically by mean of clamps or bolts.

\section{B. Catalytic system}

The catalytic bed consists of two cordierite monolith substrates with $8 \mathrm{~mm}$ diameter and $20 \mathrm{~mm}$ length that have been coated with a $10 \mathrm{wt} . \% \mathrm{Pt} / \mathrm{SiO}_{2}$ powder catalyst and colloidal silica as binder. This is the so-called supported catalyst where silica is the support and platinum is the active phase. Platinum was already recognized in the beginning of the 20th century ${ }^{24}$ to be highly active for catalytic oxidation reactions as are other precious metals such as palladium and rhodium. Here platinum is chosen because storage of hydrogen or oxygen is low as compared to, for example, palladium-based catalysts. ${ }^{25-27}$ A Pt-based catalyst is also sufficiently robust and cheaper than rhodium containing catalysts. Considering the support material, the main reason for using silica over other traditional high surface area metal oxides such as alumina or ceria is due to its lower affinity to adsorb water. ${ }^{28}$ This facilitates rapid response, i.e., start-up/shut-down and step- and pulse-response


FIG. 1. Schematic drawings of the portable water vapor generator device with dimensions in $\mathrm{mm}$. 
experiments, of the device, which is considered to be more important than preserved dispersion of the platinum phase over time. Silica is known to interact more weakly with precious metals than alumina and ceria, which may lead to sintering of the precious metal phase and reduced activity. Hydrogen oxidation, however, over precious metals is rapid and possible sintering is not an issue at the temperatures used here.

The 10 wt. $\% \mathrm{Pt} / \mathrm{SiO}_{2}$ powder catalyst was prepared using incipient wetness impregnation. $\mathrm{SiO}_{2}$ powder (Kromasil Silica KR-300-10, Akzo Nobel Eka Chemicals) was initially pretreated in air at $450{ }^{\circ} \mathrm{C}$ to remove carbonaceous contamination. A specific amount of tetraammineplatinum(II) nitrate (Alfa Aesar) was added dropwise to the $\mathrm{SiO}_{2}$ powder so as to target a platinum loading of $10 \mathrm{wt}$ \%. Milli-Q water $(18 \mathrm{M} \Omega \mathrm{cm})$ was then added during gentle stirring to saturate the pores of the silica support and promote high dispersion of the platinum phase. The obtained paste was frozen with liquid nitrogen and freeze-dried for $14 \mathrm{~h}$. The dry powder sample was calcined in air at $450^{\circ} \mathrm{C}$ for $2 \mathrm{~h}$ using a heating ramp of $5{ }^{\circ} \mathrm{C} / \mathrm{min}$. The specific surface area of the prepared powder catalyst was determined to be $114 \mathrm{~m}^{2} / \mathrm{g}$ by the BrunauerEmmett-Teller (BET) method using a Micromeritics Tristar 3000 instrument. Characterization of the average Pt particle size was performed by powder X-ray diffraction using a Bruker AXS D8 ADVANCE diffractometer. The average Pt particle diameter was calculated to be about $20 \mathrm{~nm}$ by the DebyeScherrer equation using the full width at half maximum value for the diffraction peak at a $2 \theta$ angle of $40^{\circ}$.

Two cordierite monolith substrates (Corning, Inc., 400 cpsi, 6 mill) with a diameter of $8 \mathrm{~mm}$ and a length of $20 \mathrm{~mm}$ were cut out from a commercial honeycomb structure. Washcoating was then carried out by dipping the monoliths in a continuously stirred slurry of $10 \mathrm{wt} . \% \mathrm{Pt} / \mathrm{SiO}_{2}$ powder catalyst, colloidal silica (Ludox AS-40, Sigma-Aldrich), Milli-Q water, and ethanol. The coated monolith substrates were dried in air at $80^{\circ} \mathrm{C}$ under a heat gun for $4 \mathrm{~min}$, followed by $2 \mathrm{~min}$ of calcination at about $500{ }^{\circ} \mathrm{C}$, also in air. The procedure was repeated until the monoliths had gained a weight of about $230 \mathrm{mg}$. The coated monolith substrates were finally calcined in a furnace at $450^{\circ} \mathrm{C}$ for $2 \mathrm{~h}$ with a heating rate of $5^{\circ} \mathrm{C} / \mathrm{min}$.

\section{Laboratory chemical flow reactor system}

Operational studies require a versatile feed gas delivery system to ensure a gas feed that is well-controlled and variable on demand. In the present case, a laboratory chemical flow reactor, described elsewhere, ${ }^{29}$ was used for operational evaluation of the portable water generator device at relatively high flow. Briefly, a total flow of $1000 \mathrm{ml} / \mathrm{min}$, of a desired gas mixture of $\mathrm{H}_{2}$ and $\mathrm{O}_{2}$ with argon as balance, was fed through the PWG device by g-MFCs provided by Bronkhorst. This flow correlates to a gas hourly space velocity (GHSV) for the PWG of about $7200 \mathrm{~h}^{-1}$, which is approximately one order of magnitude lower than the theoretically determined value above which a hydrogen and/or oxygen slip is expected to occur.

Furthermore, the flow reactor was equipped with a commercial CEM system (Bronkhorst) connected downstream of the PWG device. A steady carrier flow of $500 \mathrm{ml} / \mathrm{min}$ argon heated to $150^{\circ} \mathrm{C}$ was continuously kept to avoid backflow. The CEM system was partly used to ensure that the calibrated water concentrations were correct and partly used to demonstrate that the PWG device could be used complementary with the CEM system to span from low to high water concentrations, i.e., 1000 vol.-ppm to 12 vol. \%. All g-MFCs and the l-MFC were controlled by a standard personal computer (PC) via a LabVIEW interface.

The total flow fed to the laboratory chemical flow reactor was $1500 \mathrm{ml} / \mathrm{min}$. In the present case, the quartz tube of the chemical reactor was empty so as to measure the performance of the PWG device alone. However, the gas flow through the quartz tube was heated to $200^{\circ} \mathrm{C}$ to prevent vapour condensation using the ordinary heating system that consists of a type K thermocouple, a PID regulator (Eurotherm 3508), and a metal coil surrounding the quartz tube. The operational performance was monitored by analysing the effluent gas stream by both a gas phase Fourier transform infrared spectrometer (MKS 2030 HS) and a mass spectrometer (Hiden Analytical, HPR-20 QIC).

\section{Operando infrared spectrometer system}

The primary goal of the PWG device is to provide wellcontrolled low concentrations of ultra-pure water vapor to small chemical flow reactors and small flow reactors for spectroscopic measurements that demand low flows, i.e., around $100 \mathrm{ml} / \mathrm{min}$. To demonstrate such applicability, the device was connected to an operando Fourier transform infrared spectrometer system. ${ }^{30}$ This system consists of a feed gas delivery system (Bronkhorst g-MFCs) and a Praying Mantis hightemperature reaction chamber (Harrick, Inc.). The feed gas composition and the reaction chamber temperature were controlled by a PC using a LabVIEW interface. The spectrometer is a BRUKER Vertex 70 spectrometer equipped with a nitrogen cooled MCT detector. A Hiden HPR-20 QIC mass spectrometer was connected downstream the reaction chamber, following the $\mathrm{m} / \mathrm{z}$ ratios $2\left(\mathrm{H}_{2}\right), 15\left(\mathrm{CH}_{4}\right), 18\left(\mathrm{H}_{2} \mathrm{O}\right), 28(\mathrm{CO}), 40(\mathrm{Ar})$, and $44\left(\mathrm{CO}_{2}\right)$.

As an example on a sensitive spectroscopic measurement, the inhibiting effect of water vapor on methane oxidation over a typical methane oxidation catalyst consisting of a $\gamma-\mathrm{Al}_{2} \mathrm{O}_{3}$ support impregnated with $1 \mathrm{wt}$. \% Pd was studied using a total flow of $100 \mathrm{ml} / \mathrm{min}$. A $40 \mathrm{mg}$ powder catalyst was placed on top of a layer of $\mathrm{KBr}$ powder located on a metal grid in the sample holder. After pre-treatment in oxidizing conditions at $550^{\circ} \mathrm{C}$, the temperature set point was decreased to $400^{\circ} \mathrm{C}$ where a background spectrum was recorded. The effect of water on the oxidation of methane was then studied by keeping the inlet flow of methane $(0.15 \%)$ and oxygen $(2 \%)$ constant and stepwise increasing the vapor concentration from 0 to $1.0 \mathrm{vol} . \%$. The incremental step was initially $0.1 \%$ units up to $0.5 \%$ and then increased to $0.25 \%$ units. The PWG device was here operating in $2 \% \mathrm{O}_{2}$ excess with a flow of $50 \mathrm{ml} / \mathrm{min}$, corresponding to a GHSV of $360 \mathrm{~h}^{-1}$. In order to ensure a rapid response of the increased water vapor concentration, the outlet tube was heated to $120^{\circ} \mathrm{C}$ using a heating band and also placed close to the reaction chamber. 


\section{RESULTS AND DISCUSSION}

\section{A. Safety considerations}

First, we comment on one aspect that always should be carefully treated when using hydrogen in the presence of oxygen, namely, the risk of explosion. The under and upper explosion limits of hydrogen in air at room temperature are 4 and 75 vol. \%, respectively. ${ }^{31}$ Increased $\mathrm{O}_{2}$ concentration and/or temperature and pressure result in an even wider range of hydrogen concentrations forming gas mixtures prone to explode. The limiting oxygen concentration (LOC), for which hydrogen combustion cannot take place, is $4.6 \mathrm{vol} . \% \mathrm{O}_{2}$ when diluted in nitrogen. ${ }^{31}$ This is because the inert gas quenches the reaction and prevents flame propagation. According to the 2:1 stoichiometric molar ratio of hydrogen to oxygen, this allows a safe water vapor formation up to at least 9 vol. \%. In this study, however, we conservatively limit the generation of water vapor to 3 vol. \% due to other circumstances, i.e., reducing the risks of forming volatile platinum species due to either high exotherms in the device during hydrogen oxidation or dissolution of weakly bound Pt entities by high water content (less likely). Extended operation can otherwise in a worst case scenario lead to catalyst deterioration and severe Pt contamination of downstream reactor systems.

Another issue that may limit the applicability of the device is its external temperature. Figure 2 shows the temperature on the external metal shield as a function of the operation temperature. As can be seen, the surface temperature does not exceed $60^{\circ} \mathrm{C}$ when operated below $300^{\circ} \mathrm{C}$. The water reactor can hence be placed in the vicinity of other equipment without exposing a risk of damage.

\section{B. Generation of water vapor for chemical flow reactor experiments}

The results from the use of the water vapor device together with a chemical flow reactor are displayed in Fig. 3, which shows the outlet gas concentrations of $\mathrm{H}_{2}$ and $\mathrm{O}_{2}$ as measured by mass spectrometry and $\mathrm{H}_{2} \mathrm{O}$ as measured by FTIR spectroscopy. The light blue dots indicate that the water signal has some noise. The blue line, obtained by taking an average of 20 experimental values, confirms that the device delivers water vapor with high accuracy at both low and high concentrations using a relatively high flow. The measured $\mathrm{H}_{2} \mathrm{O}, \mathrm{H}_{2}$, and $\mathrm{O}_{2}$ outlet concentrations correlate well to the set points

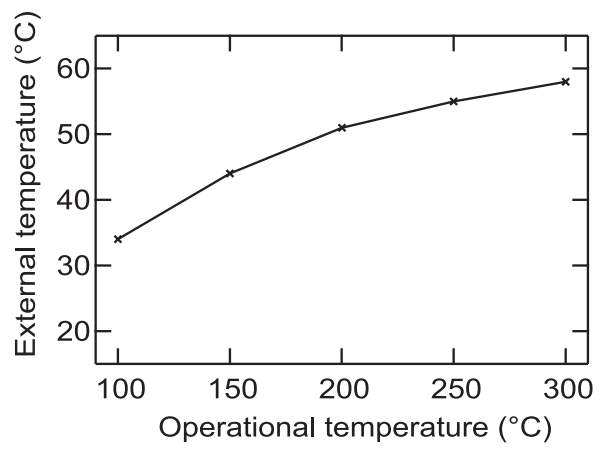

FIG. 2. Operational temperature plotted against external metal shield temperature.


FIG. 3. Generation of $0-1.5$ vol. \% water vapor in (a) 0.5 vol. \% oxygen excess, (b) stoichiometric conditions, and (c) $0.5 \mathrm{vol} . \%$ hydrogen excess with argon balance and a total flow of $1500 \mathrm{ml} / \mathrm{min}$. The water signal was smoothed out by averaging 20 experimental values per each created data point.

when ramping from 0 to 1.5 vol. $\%$ water vapor with incremental steps of 0.1 vol. \% in lean (a), stoichiometric (b), and rich (c) conditions. It has been shown that residual (contaminant) water in gas bottles can affect IR measurements at low pressure. ${ }^{32}$ Generation of ppm level water could hence be crucial to confirm and increase the fundamental understanding of such effects.

We comment the inconsistency of using two analysis instruments in Fig. 3 to be due to a less stable water signal from the mass spectrometer that could detect hydrogen and oxygen. Further, if one of the two reactants is unwanted, i.e., in a case where either $\mathrm{O}_{2}$ or $\mathrm{H}_{2}$ must be avoided, the PWG device can be 


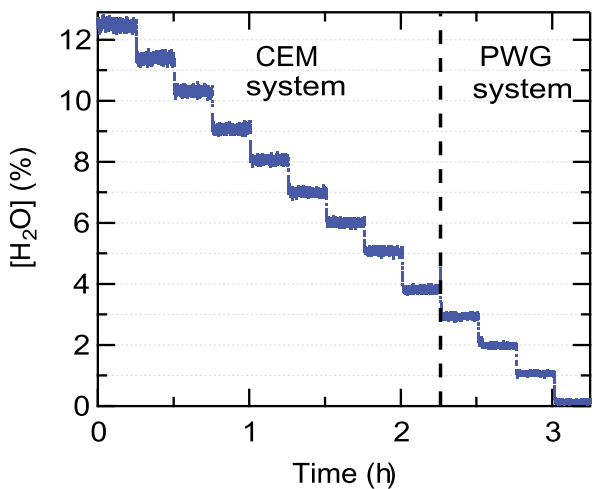

FIG. 4. Combined water vapor ramp via a controlled evaporation mixing system (12-4 vol. \%) and the PWG device (3-1 vol. \%) operating in 2\% $\mathrm{O}_{2}$ excess with argon balance and a total flow of $1500 \mathrm{ml} / \mathrm{min}$.

operated in either the hydrogen or oxygen excess mode as the limiting reactant is then fully converted [cf. panels (a) and (c)].

Although the main function of the PWG is to provide wellcontrolled low concentrations of ultra-pure water to laboratory apparatuses, there may be situations where the need for high purity water is not crucial but spanning a large concentration interval is of prime interest. In Fig. 4, a stepwise water ramp spanning a large concentration interval is created by combining the present PWG device with a commercial CEM system. The water vapor concentration is initially decreased from 12 to 4 vol. \% with a 1 vol. \% decrease every 900 s using the CEM system. It was not possible to deliver 3 vol. \% water vapor at a flow rate of $1500 \mathrm{ml} / \mathrm{min}$ due to limitations of the $1-M F C$. This can be solved by switching to the PWG system, as indicated by the dashed line in Fig. 4, here operating in $2 \% \mathrm{O}_{2}$ excess. As can be seen, the PWG device complement the commercial system well and it is shown that the switch of the water delivery system occurs smoothly.

\section{Influence of water on catalytic oxidation of methane studied by operando diffusive reflectance FTIR spectroscopy}

The results from the combined DRIFTS and mass spectrometry measurements acquired during a stepwise increased inlet water vapor concentration (0-1.0 vol. \%) in an otherwise constant flow of methane $(0.15 \%)$ and oxygen $(2.0 \%)$ are shown in Fig. 5. The reaction mixture was passed through a bed with 1 wt. $\% \mathrm{Pd} / \gamma-\mathrm{Al}_{2} \mathrm{O}_{3}$ heated to $400{ }^{\circ} \mathrm{C}$. Figure 5 , panel (a) shows the IR spectra for the $\mathrm{OH}$-stretching region during methane oxidation in dry conditions and in the presence of $1.0 \% \mathrm{H}_{2} \mathrm{O}$. In panel (b), the continuous change in IR peak area for gas phase $\mathrm{CO}_{2}\left(2350 \mathrm{~cm}^{-1}\right)$ and surface-bound $\mathrm{OH}$ species $\left(3507,3692 \text {, and } 3734 \mathrm{~cm}^{-1}\right)^{33}$ is shown, and in panel (c), the corresponding changes in overall $\mathrm{CH}_{4}$ conversion and $\mathrm{H}_{2} \mathrm{O}$ concentration in the effluent stream are displayed. As can be seen, the initial $\mathrm{CH}_{4}$ conversion in the absence of water vapor is about $30 \%$. The catalytic activity then gradually decreases as the water concentration in the inlet gas feed as provided by the PWG device increases. For the last reaction steps, when the water vapor concentration is increased to 0.75 and 1.0 vol. \%, the methane conversion becomes negligible. A similar trend is observed as the integrated IR peak area of the reaction product, $\mathrm{CO}_{2}$, is monitored. The experiment clearly reveals

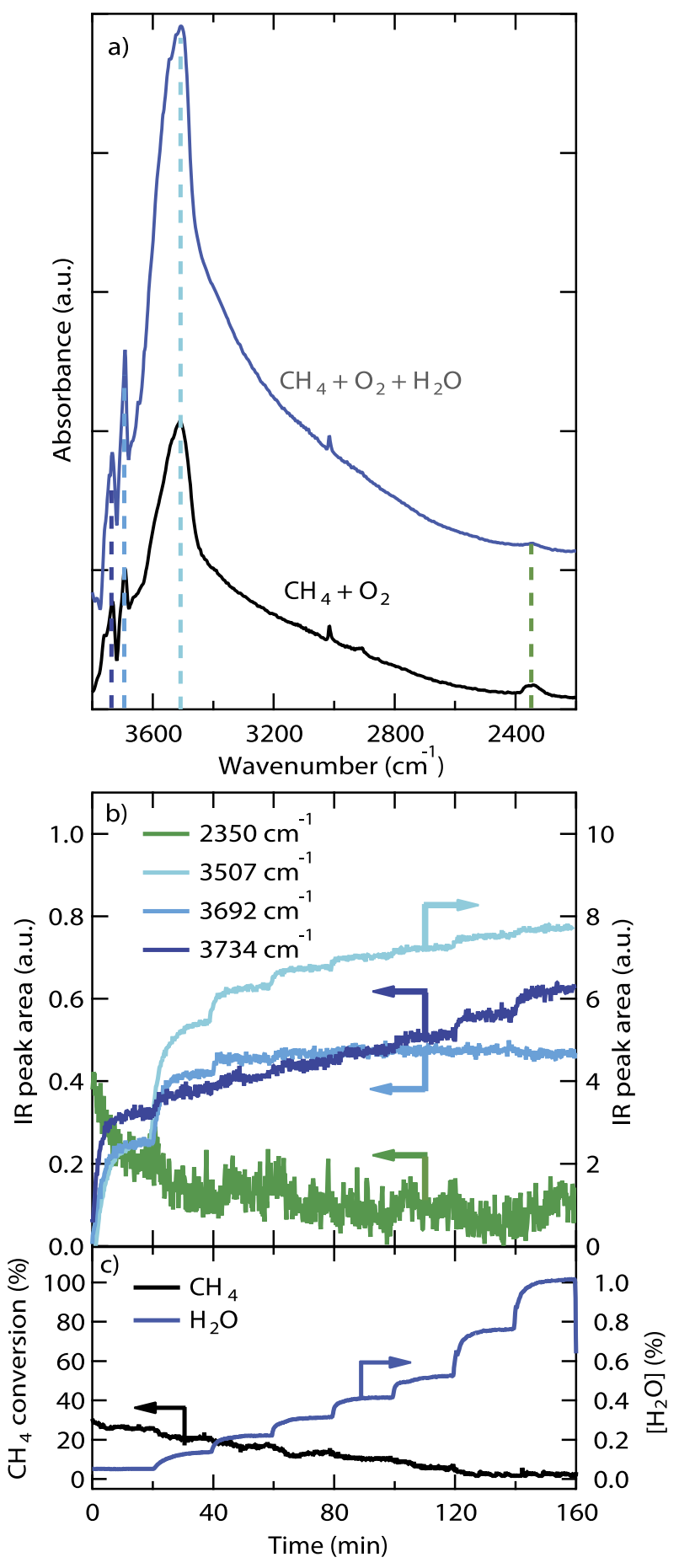

FIG. 5. (a) shows DRIFTS spectra recorded in $0.15 \% \mathrm{CH}_{4}+2.0 \% \mathrm{O}_{2}$ (bottom) and $0.15 \% \mathrm{CH}_{4}+2.0 \% \mathrm{O}_{2}+1.0 \% \mathrm{H}_{2} \mathrm{O}$ (top) with argon balance and a total flow of $100 \mathrm{ml} / \mathrm{min}$ at $400{ }^{\circ} \mathrm{C}$. (b) illustrates a decreased IR absorption from $\mathrm{CO}_{2}$ at $2350 \mathrm{~cm}^{-1}$ and an increased absorption from surface-bound $\mathrm{OH}$ species at 3507,3692 , and $3734^{-1}$ as IR peak areas while increasing the inlet water vapor concentration. In (c), the $\mathrm{CH}_{4}$ conversion is monitored as well as the increased concentration of water vapor.

that addition of low amounts of ultra-pure water vapor leads to an increased build-up of surface-bound $\mathrm{OH}$ species. The increased hydroxyl coverage is certainly linked to the inhibiting effect of water vapor on the catalytic activity for methane oxidation over alumina supported palladium catalysts.

Furthermore, catalytic oxidation of hydrogen allows advanced types of isotopic labeling experiments with either 
deuterium, ${ }^{18} \mathrm{O}_{2}$, or both. The possibility to rapidly switch between isotopes and thus label water may add value to both chemical selectivity studies in chemical flow reactors equipped with mass spectrometers/infrared analyzers as well as to infrared spectroscopic measurements of surface species for which vibrational band shifts can reveal more detailed information about surface species, catalyst properties, and reaction mechanisms.

\section{CONCLUDING REMARKS}

In the present work, we have outlined the development and function of an easy-to-use portable device for the generation of ultra-pure water vapor. The device is small, robust, easy to build, and cheap. Further it is easily installed alongside existing gas systems, making it suitable for temporary use outside home laboratories, e.g., research facilities such as synchrotrons. We have shown that the device can repeatably generate water vapor of low concentrations for both low and high flow rates with high accuracy. Operation under non-stoichiometric conditions can exclude the minority component, hydrogen or oxygen, from the gas stream. Finally, we demonstrate a case reaction where the device is used in a sensitive operando spectroscopic measurement of the inhibiting effect of water vapor on the catalytic oxidation of methane over a Pd-based methane oxidation catalyst.

\section{ACKNOWLEDGMENTS}

This work was financially supported by the Swedish Energy Agency through the FFI program "Fundamental studies on the influence of water on oxidation catalyst for biogas applications" (No. 40274-1) and the Competence Centre for Catalysis, which is hosted by Chalmers University of Technology and financially supported by the Swedish Energy Agency and the member companies AB Volvo, ECAPS AB, Haldor Topsøe A/S, Scania CV AB, Volvo Car Corporation AB, and Wärtsilä Finland $\mathrm{Oy}$.

${ }^{1}$ T. Maillet, J. Barbier, and D. Duprez, Appl. Catal., B 9, 251 (1996).

${ }^{2}$ J. C. van Giezen, F. R. van den Berg, J. L. Kleinen, A. J. van Dillen, and J. W. Geus, Catal. Today 47, 287 (1999).

${ }^{3}$ D. Ciuparu and L. Pfefferle, Appl. Catal., A 209, 415 (2001).

${ }^{4}$ R. Caporali, S. Chansai, R. Burch, J. J. Delgado, A. Goguet, C. Hardacre, L. Mantarosie, and D. Thompsett, Appl. Catal., B 147, 764 (2014).
${ }^{5}$ C. Wang, X.-K. Gu, H. Yan, Y. Lin, J. Li, D. Liu, W.-X. Li, and J. Lu, ACS Catal. 7, 887-891 (2017); e-print arXiv:1408.1149.

${ }^{6}$ S. R. J. Saunders, M. Monteiro, and F. Rizzo, Prog. Mater. Sci. 53, 775 (2008).

${ }^{7}$ N. S. Jacobson, E. J. Opila, and K. N. Lee, Curr. Opin. Solid State Mater. Sci. 5, 301 (2001).

${ }^{8}$ J. Ehlers, D. J. Young, E. J. Smaardijk, A. K. Tyagi, H. J. Penkalla, L. Singheiser, and W. J. Quadakkers, Corros. Sci. 48, 3428 (2006).

${ }^{9}$ E. Essuman, G. H. Meier, J. Zurek, M. Hänsel, and W. J. Quadakkers, Oxid. Met. 69, 143 (2008).

${ }^{10}$ C. L. Soles and A. F. Yee, J. Polym. Sci., Part B: Polym. Phys. 38, 792 (2000).

${ }^{11}$ F. Lapique and K. Redford, Int. J. Adhes. Adhes. 22, 337 (2002).

${ }^{12}$ W. K. Loh, A. D. Crocombe, M. M. A. Wahab, and I. A. Ashcroft, Int. J. Adhes. Adhes. 25, 1 (2005).

${ }^{13}$ F. Dubelley, E. Planes, C. Bas, E. Pons, B. Yrieix, and L. Flandin, J. Phys. Chem. B 121, 1953 (2017).

${ }^{14}$ D. C. Hovde, J. T. Hodges, G. E. Scace, and J. A. Silver, Appl. Opt. 40, 829 (2001).

${ }^{15}$ T. Ohkawa, O. Nakamura, H. Aharoni, and T. Ohmi, Thin Solid Films 405, 290 (2002).

${ }^{16} \mathrm{~S}$. Hoshino, M. Yoshida, S. Uemura, T. Kodzasa, N. Takada, T. Kamata, and K. Yase, J. Appl. Phys. 95, 5088 (2004).

${ }^{17}$ J. L. Hartley, Rev. Sci. Instrum. 49, 1647 (1978).

${ }^{18}$ T. Huthwelker, V. Zelenay, M. Birrer, A. Krepelova, J. Raabe, G. Tzvetkov, M. G. C. Vernooij, and M. Ammann, Rev. Sci. Instrum. 81, 113706 (2010).

${ }^{19}$ S. T. Kelly, P. Nigge, S. Prakash, A. Laskin, B. Wang, T. Tyliszczak, S. R. Leone, and M. K. Gilles, Rev. Sci. Instrum. 84, 073708 (2013).

${ }^{20}$ T. Ahmido, W. A. Kimes, B. A. Sperling, J. T. Hodges, and J. E. Maslar, J. Vac. Sci. Technol., A 34, 031512 (2016).

${ }^{21}$ C. N. Millet, R. Chédotal, and P. Da Costa, Appl. Catal., B 90, 339 (2009).

${ }^{22}$ T. Ohmi, Y. Minami, K. Kawada, Y. Tanabe, N. Ikeda, and A. Morimoto, "Method for generating water for semiconductor production," U.S. patent 6,093,662 A (25 June 2000).

${ }^{23}$ S. S. Chell and S. Jose, U.S. patent 6,524,934 B1 (25 February 2003).

${ }^{24}$ P. M. D. Collins, Platinum Met. Rev. 30, 141 (1986).

${ }^{25}$ E. Becker, P. A. Carlsson, H. Grönbeck, and M. Skoglundh, J. Catal. 252, 11 (2007).

${ }^{26}$ A. Trinchero, A. Hellman, and H. Grönbeck, Surf. Sci. 616, 206 (2013).

${ }^{27}$ S. M. Kozlov, H. A. Aleksandrov, and K. M. Neyman, J. Phys. Chem. C 119, 5180 (2015).

${ }^{28}$ D. Bounechada, S. Fouladvand, L. Kylhammar, T. Pingel, E. Olsson, M. Skoglundh, J. Gustafson, M. Di Michiel, M. A. Newton, and P.-A. Carlsson, Phys. Chem. Chem. Phys. 15, 8648 (2013).

${ }^{29}$ E. C. Adams, M. Skoglundh, and P.-A. Carlsson, Catal. Commun. 95, 26 (2017).

${ }^{30}$ N. Martin, P. Velin, M. Skoglundh, M. Bauer, and P.-A. Carlsson, Catal. Sci. Technol. 7, 1086 (2017).

${ }^{31}$ I. A. Zlochower and G. M. Green, J. Loss Prev. Process Ind. 22, 499 (2009).

${ }^{32}$ G. Rupprechter, T. Dellwig, H. Unterhalt, and H. J. Freund, J. Phys. Chem. B 105, 3797 (2001).

${ }^{33}$ H. Knözinger and P. Ratnasamy, Catal. Rev. 17, 31 (1978). 